\title{
Unprepared: A Qualitative Exploration of the Preparation Practices of SLPs Practicing in Urban Schools
}

Audrey M. Farrugia-Bernard

Eastern Michigan University, abernar5@emich.edu

DOI: doi.org/10.30707/TLCSD2.3Farrugia-Bernard

Follow this and additional works at: https://ir.library.illinoisstate.edu/tlcsd

Part of the Scholarship of Teaching and Learning Commons

\section{Recommended Citation}

Farrugia-Bernard, Audrey M. (2018) "Unprepared: A Qualitative Exploration of the Preparation Practices of SLPs Practicing in Urban Schools," Teaching and Learning in Communication Sciences \& Disorders: Vol. 2: Iss. 3 , Article 2.

DOI: doi.org/10.30707/TLCSD2.3Farrugia-Bernard

Available at: https://ir.library.illinoisstate.edu/tlcsd/vol2/iss3/2

This Scholarship of Teaching and Learning Research is brought to you for free and open access by ISU ReD: Research and eData. It has been accepted for inclusion in Teaching and Learning in Communication Sciences \& Disorders by an authorized editor of ISU ReD: Research and eData. For more information, please contact ISUReD@ilstu.edu. 


\title{
Unprepared: A Qualitative Exploration of the Preparation Practices of SLPs Practicing in Urban Schools
}

\author{
Abstract \\ The field of speech-language pathology severely lacks diversity, yet speech language pathologists serve \\ an increasingly diverse population in schools. This qualitative study explored the academic preparation \\ practices of speech-language pathologists working in urban schools. The findings revealed that the \\ participants felt they were not adequately prepared to work in urban schools with children from culturally \\ and linguistically diverse backgrounds independent of the model of multicultural education that they \\ received in their graduate education. Results suggest that we need to connect multicultural coursework to \\ local, urban communities in order to better prepare speech-language pathologists to work in urban \\ schools.
}

\section{Keywords}

Cultural and Linguistic Diversity, Multicultural, Urban Education 
The field of speech-language pathology severely lacks diversity, yet speech language pathologists (SLPs) serve an increasingly diverse population in schools. According to the American Speech-Language-Hearing Association (ASHA) in 2016, only 7.9\% of speech language pathology affiliates across the country self-identified as a "racial minority" (ASHA, 2017). This can be compared to 50.5\% of students identified as Black, Hispanic, Asian/Pacific Islander, American Indian/Alaska Native, or two or more races enrolled in public elementary and secondary schools in the United States (National Center for Education Statistics, 2017). This racial/cultural mismatch is especially important to examine considering the majority of SLPs work in school settings (ASHA, 2017). Furthermore, Villegas and Irvine (2010) maintained that a diverse school staff is important because professionals of color serve as role models for all students, are more likely to work in high-need urban schools, and have the potential to improve school experiences and academic outcomes for students of color.

\section{Urban Education}

High concentration of culturally and linguistically diverse (CLD) students in urban schools is not a new phenomenon. "Culturally and linguistically diverse" is a category and term used by the United States Department of Education to denote students who are not proficient in or possess a limited proficiency in Standard American English language and/or come from diverse social, cultural, or economic backgrounds (Gonzalez, Pagan, Wendell, \& Love, 2011). Urban schools have been "minority-majority" for quite some time with approximately two-thirds of students in urban schools classified as a CLD student of color (Kincheloe, 2007). A consensus on an exact definition of urban education does not exist. Consequently, two definitions of urban education (Kincheloe, 2007; Milner, 2012) are presented in an effort to contextualize the information introduced in this study. Kincheloe (2007) outlined 12 characteristics of urban schools. Urban schools

- operate in areas with high population density;

- are bigger and serve more students;

- function in areas marked by profound economic disparity;

- have a higher rate of ethnic, racial, and religious diversity;

- experience factionalized infighting on school boards over issues concerning resources and influence;

- are undermined by ineffective business operations;

- $\quad$ are more likely to work with students who experience health problems;

- experience higher student, teacher, and administrator mobility;

- serve higher immigrant populations; are characterized by linguistic diversity;

- experience unique transportation problems;

- employ teachers who are less likely to live in the poor communities surrounding the schools than teachers in suburban and rural systems.

Milner (2012) offered three conceptual frames to define urban education: urban intensive, urban emergent, and urban characteristic. Urban intensive education describes those schools situated in large, densely populated, metropolitan cities. Urban emergent schools are located in cities that are not quite as large or populated as the ones found in the urban intensive category but share the challenges, such as lack of resources. Urban characteristic schools are not located in large cities but experience some of the challenges of an urban environment such as an in increase in English Language Learners (ELL). 


\section{Multicultural Preparation}

The growth of diversity in the United States increases the likelihood that SLPs will work with CLD individuals. For this reason, ASHA requires that graduate programs in speech-language pathology, "must be specifically designed to prepare students for entry into professional practice and provide curriculum (academic and clinical education) that reflects current knowledge, skills, technology, scopes of practice, and the diversity of society" (ASHA, n.d.-b, para. 1). In addition, ASHA mandates that students must complete practica that include direct contact with CLD clients (Council for Clinical Certification in Audiology and Speech-Language Pathology of the American Speech-Language-Hearing Association, 2013). While ASHA (n.d.-b) does offer resources to faculty in higher education in the form of a guide to clinical competence in the curriculum, resources to infuse multicultural issues into coursework, and sample syllabi for foundational multicultural courses, the methods for accomplishing these tasks are left up to individual speech-language pathology programs, resulting in a large variety of multicultural preparatory practices.

The two major approaches for incorporating multicultural content into speech and language programs are known as infusion and foundational course approaches (ASHA, n.d.-b). The infusion approach involves embedding content about CLD populations into one or more courses across the curriculum. This is the approach most speech-language pathology programs utilize (Stewart \& Gonzalez, 2002; Stockman, Boult, \& Robinson, 2004). The foundational course approach involves the creation and implementation of one or more courses dedicated solely to multicultural content. ASHA maintains that because the infusion approach is often not implemented with fidelity, the best method for multicultural preparation involves a combination of both the infusion and foundational course approaches (ASHA, n.d.-b; Stockman, Boult, \& Robinson, 2004). However, there are no standard approaches for clinical practicum experiences with CLD clients (Sheepway, Lincoln, \& Togher, 2011; Stewart \& Gonzalez, 2002).

Related disciplines have similar approaches to multicultural preparation. For example, physical therapy educators have been given the instruction to incorporate cultural competence education in their coursework and clinical experiences but with vague directives:

Application of the theories, principles, and practices for advancing education in cultural competence may be achieved through the use of case studies, problem-based learning, community service and engagement activities, clinical case reporting, and clinical education experiences strategically placed throughout the curriculum (American Physical Therapy Association, 2014).

Teacher education preparation programs' response to the cultural mismatch between teacher and student has been to add a course or content that focuses on multiculturalism to the curriculum (Mustian, Lee, Nelson, Gamboa-Turner, \& Roule, 2017; Zeichner, 2003). In reimagining teacher education programs to better prepare individuals for working with CLD students, researchers have more recently advocated for a "third" or "hybrid" space where curriculum, school and community partners, and families come together to provide a holistic approach to preparing teacher candidates for work in urban schools (Robertson, García, McFarland, \& Rieth, 2012; Zeichner, 2010). This praxis-style approach is particularly meaningful as it is commonly accepted in the field of teacher education that pre-service field experiences are the most 
influential part of preparation practices (Ronfeldt, 2012; Wilson, Floden, \& Ferrini-Mundy, 2001).

Despite multicultural coursework and the push for cultural competence, only $8 \%$ of surveyed school SLPs felt very qualified to address cultural and linguistic influences on service delivery and outcomes (ASHA, 2016). The purpose of this study is to investigate the preparation experiences of SLPs working in urban schools with CLD students. While researchers have examined the preparation of teachers working in urban schools (Bales \& Saffold, 2011; LadsonBillings, 1999; Milner, 2006), a limited number have examined how SLPs are prepared to practice in urban settings (Stewart \& Gonzalez, 2002; Stockman, Boult, \& Robinson, 2004). Understanding SLPs' preparation experiences for working in urban schools is essential for forming higher education policies and practices that will allow for the equitable education of urban students. As such, this project is an important, unique addition to the small but growing body of literature on the scholarship of teaching and learning and cultural and linguistic diversity in the field of speech-language pathology.

\section{Method}

This qualitative investigation employed a phenomenological approach. Phenomenology is a qualitative research approach that seeks to understand a lived experience from the participants' perspective (Schram, 2006). The phenomenological paradigm employs a constructivist approach in which individuals construct their own distinct perspective of the world (Glesne, 2006). Phenomenological inquiry is not done with the intention to generalize the results but rather to yield interpretive understanding, based on the examination of the experiences and perspectives of individuals (Brantlinger, Jimenez, Klingner, Pugach, \& Richardson, 2005).

Data collection. Data collection began after receiving Institutional Review Board approval in December, 2015. School-based speech-language pathologists, who held or were working toward a certificate of clinical competence (CCC) granted from ASHA, working in an urban school district in the Midwest, were eligible for the study. The snowball method of recruitment was utilized in this study. Participants were assigned a pseudonym and a fictitious name of their school to protect their identity. All of the participants were White females. This sample was not purposefully homogenous by race and gender, rather, it reflects the reality that the field of speech-language pathology in the United States severely lacks diversity. Participants were between the ages of 24 and 60 with a mean of 35 years old. The participants were employed either directly for a school district or through a contract company and then placed in an urban school. See Table 1 for participant demographic information. Initial interviews were conducted with a larger sample group of 13 individuals. Follow-up interviews were conducted with 11 participants and were the focus of this study. The two participants who were excluded were completing their clinical fellowship (CF) year. It was difficult to determine how inexperience in the field of speech-language pathology impacted their responses, and as such, the researcher chose not to include their narratives in this study. 
Table 1. Participant Demographics

\begin{tabular}{cccc}
\hline & $\begin{array}{c}\text { Urban Intensive } \\
\text { School Employee }\end{array}$ & $\begin{array}{c}\text { Urban Emergent } \\
\text { School Employee }\end{array}$ & $\begin{array}{c}\text { Urban Characteristic } \\
\text { School Employee }\end{array}$ \\
\hline $\begin{array}{c}\text { 1-5 years of practice } \\
\text { in urban schools }\end{array}$ & $\begin{array}{c}\text { Allison } \\
\text { Casey } \\
\text { Rachel }\end{array}$ & $\underline{\text { Anna }}$ & Stacey \\
\hline $\begin{array}{c}\text { 6-10 years of practice } \\
\text { in urban schools }\end{array}$ & Abby & $\underline{\underline{\text { Baroline }}}$ & $\underline{\underline{\text { Erin }}}$ \\
\hline $\begin{array}{c}\text { 11+ years of practice } \\
\text { in urban schools }\end{array}$ & & $\underline{\underline{\text { Jennifer }}}$ \\
\hline
\end{tabular}

Note. Direct employees of school districts, not working for contract companies, are italicized and underlined.

Semi-structured, in-depth initial interviews that made use of a three-part process of focused life history, details of the experience, and reflection on meaning (Seidman, 2006) as well as followup interviews for data clarification were audio-recorded and completed by the researcher. All interviews were completed in person by the researcher. Initial interviews lasted approximately an hour and follow-up interviews approximately 30 minutes. Transcription of the interviews was completed, with pseudonyms in place, from a reputable, professional transcription service. The transcriptionist was knowledgeable of the health insurance portability and accountability act (HIPAA), family educational rights and privacy act (FERPA), and institutional review board practices for protecting participant identity. Ethnographic data gathering methods, in the form of observations of Individualized Education Plan meetings and/or treatment sessions, were also conducted by the researcher, which allowed for the understanding of the participants' constructions of reality as well as the opportunity to recognize "patterns in their perspectives and behaviors" (Glesne, 2006, p. 9). Observation notes, which made use of what Geertz (1973) has termed thick description, were also completed. Thick description moves beyond precise narrative transcription and includes rich description of the paralinguistic and nonverbal cues as well as the environment.

Data analysis. In order to understand the preparation experiences of the participants, the researcher analyzed the interview transcriptions and observation notes. A modified version of Hycner's (1985) steps for phenomenological data analysis was followed: transcription of interviews, bracketing (suspending belief so as to enter with no preconceived attitudes or opinions), listening to the interview for a sense of the whole, delineating units of general 
meaning, delineating units of meaning relevant to the research questions, eliminating redundancies, clustering units of meaning, determining themes from clusters of meaning; summarizing each interview, modifying themes, identifying general and unique themes for all interviews, contextualizing of themes, and creating of a composite summary.

Following each interview or observation, the researcher recorded her thoughts in a research journal. This process allowed the researcher to acknowledge personal beliefs and experiences, which helped to ensure that positionality did not impact the participants' voices. Data analysis began during the data collection process, while collecting the interviews and observations. The researcher reviewed the audio recordings, transcripts, and notes in order to begin to identify commonalities among the participants' experiences. Themes, or common experiences of the participants that impart the essence of the phenomenon, (Creswell, 2013) were identified. When all interviews and observations were completed, the researcher commenced line-by-line focused coding to cluster frequently used terms and common experiences into themes. A composite approach, in which the narratives of the participants are organized and presented in themes, was chosen because it was the most effective and efficient way to illuminate the participants' various responses, both those that were similar and different, while also protecting their confidentiality.

\section{Results}

The 11 participants detailed their educational journeys. Despite the variations in the stories, each participant talked in-depth about multicultural coursework, clinical practica, and internship training, and how, ultimately, they felt these core educational experiences failed to prepare them for practice in urban schools with CLD students.

\section{Multicultural coursework: "Trying to get us to learn about other cultures."}

Foundational course approach. As Jenna revealed, it was "not until graduate school in speech pathology that the issue of diversity was directly addressed." This was the case for the majority of the participants who had completed a single, foundational course dedicated to multicultural topics in speech-language pathology. However, the participants did not feel that the multicultural course was particularly useful for their clinical practice. The single multicultural course was, as Stacey stated, "pretty much the only mention of diversity in school." Stacey explained that one of her professors "taught the one multicultural class and that was pretty much the only class I had where I was looking at language and multicultural English." Many of the participants made comments that the one single class on multicultural issues in speech-language pathology, without any other mention throughout the curriculum, was not helpful in preparing them for practice in urban schools. Anna commented disdainfully on the usefulness and practicality of the course: "We did have a multicultural class. We did talk about dialects and differences based upon different races but I don't know how much experience I actually got... it was all just out of a book." Similarly, Blair explained that the "classes kind of give the foundation for what to expect" but did not provide relevant experience for future practice.

Interestingly, Allison pointed out that her course about cultural diversity was not very diverse at all: "I think we had a class called cultural diversity but all we talked about was mostly African American Vernacular English. Nothing else really." Allison felt that the course should have been 
inclusive of more cultures and topics to be truly useful. Erin too felt frustrated with the relatively narrow definition applied to diversity and multicultural topics in her course: "We didn't really learn anything about the difference between language impairment and the kids that just don't speak our language." As she reflected on her current position, she felt information on English language learners (ELLs) would have been extremely beneficial.

Infusion approach. Conversely, Abby, Casey, and Rachel, "didn't really have any courses on cultural competence," as Rachel stated. Instead, multicultural information was worked into existing traditional courses, such as a course on language disorders, and simply infused into lectures at appropriate times. Casey explained her experience by stating, "I don't feel like we had a whole class on it [cultural competence]...I definitely remember several lectures on the subject but I don't remember ever having an actual class." Similarly, Abby recalled, "We had a professionalism course in conjunction with our fifth semester placement and we talked about it [diversity] a little bit but we had nothing of significance that I can recall." Abby, Casey, and Rachel felt that this approach did not give them adequate access to multicultural information, which negatively impacted their preparation for working in urban schools.

Jennifer pointed out that multicultural coursework was a relatively new addition to curriculum. When Jennifer was in graduate school 20 years ago, multicultural information was not "in favor" as she explained, and it was certainly not required: "That was so long ago, I know I took [a multicultural] class but I think it was a choice. It was some kind of multicultural something, I don't remember for sure but I do remember taking just one class." When Jennifer began her career, almost all of the children she served were White and from middle-class backgrounds, and so she felt at that time, a multicultural class would not have been helpful. However, since the demographics and dynamic of her school district have changed, Jennifer has taken "a couple of online courses looking at multicultural information" to supplement her knowledge and practice.

\section{Clinical practica: "Real life."}

The participants began their clinical and internship experiences where they practiced their skills servicing clients without adequate preparation from coursework for working with individuals from diverse cultures. Clinical practica experiences typically lasted for a short period of time and focused on one or two clients whereas internship experiences typically lasted a semester and included assessment and treatment for a full caseload. The participants felt their universities did not prepare them for work in urban schools and as result they felt ineffective in their practicum experiences. The switch from bookwork to working with real people was difficult for many of the participants. Erin commented, "I don't think [university] prepared people for real life." She questioned if the clients she provided service to at her university clinic reflected what she would be doing in her job when she stated, "Why did I treat them? What did that prepare me for?" The difficulty transitioning to working with clients was compounded when the participants were placed in urban schools for their clinical and/or internship experiences. These placements were often, as Jenna explained, "probably my first real experience with diversity" and thus vastly different from what the inexperienced clinicians had been exposed to throughout coursework and earlier field experiences and observations as well as their personal lives. Rachel struggled with the diversity in her clinical experiences, "I come from a town of 4,500 people so it is a small community. When my kids were growing up, there was one little Black girl who was adopted in 
the town. That's it." This was a distinct difference from what Rachel experienced in her clinicals as she explained, "All of the clients at the school were Black and then one little boy was Arabic. But for the most part they were Black." Allison too talked about the culture shock experienced in one her clinical experiences, "Basically everyone I was working with was African American. It was a total switch." She felt out of place and unprepared from the second she arrived at an urban school internship: "One of my schools was a 100\% Arabic speaking population. It was shocking pulling into the parking lot and seeing people wearing full hijab... I didn't realize the Middle Eastern population was so high." She felt embarrassed at her lack of preparation and for not knowing more about the students' culture: "I didn't know any of these things [cultural norms] until I was at the school and people were telling me." Even those participants, like Abby, who had personal experience with urban cities still felt shock working in urban schools:

My mom worked in the city so I would always come down here and spend time with her and do stuff downtown so it wasn't that I was not exposed to it, but it was definitely in a different context... It was really a culture shock working here.

Caroline commented on the fact that she felt confident enough in social situations with the urban students and families, but professionally, she felt insecure: "From a cultural perspective, I feel like I understand and feel comfortable...but in terms of being an SLP with them, I don't feel prepared."

It was not just the students' race that was different for participants. Rachel stated, "it's language structures and behaviors. Like culturally what you see here, between parents and their kids, are different than what you see where I live." Allison recalled struggling with appropriately assessing and treating students who did not speak Mainstream American English and feeling frustrated with the lack of help she received from her supervisors. She commented, "They would tell me there is a section in the PLS [Preschool Language Scales] that you can look at it and it would say something about dialect but that was it." One of the biggest differences that the participants commented on was the low socioeconomic status and environment of the urban schools. Jenna remembered, "Many of my classmates were reporting to their clinicals and saying, 'Oh my gosh, you are never going to believe where they put me! I am too scared!'” Rachel too was "very uncomfortable" with her urban internship placement because "it is like a war zone. It looks like a bomb went off there, you know, burned up buildings, knocked down buildings, abandoned everything and then two blocks over, opulence." Rachel went on to explain that "We were told when we went on those placements, we needed to be aware at all times."

Some participants had school-based internships that did not take place in urban schools. Blair, who completed her internship in a suburban school, commented on the distinct cultural differences she experienced in her all White school internship versus her multicultural work experiences in her urban characteristic school: "I don't think there was ever a time where I had to worry about culture or offending someone in my internship. Ever." Caroline too talked about the lack of diversity she experienced in her school internship placement: "very little diversity there. Very, very little. Probably the least of any place I have ever been." Similarly, Anna, who completed graduate school out of state at a small rural college, noted that diverse internships simply were not available in the rural region she attended school. Thus, for Anna beginning work in an urban environment was "mind-blowing." Blair, Caroline, and Anna expressed regret over not being pre-professionally exposed to students from diverse backgrounds earlier. 
Even though Blair, Caroline, and Anna lacked urban school experience, they at least completed fieldwork in the public school system. Abby commented that, "We didn't have a lot of school placements, unfortunately. There were a lot more down the medical path. I had a really short one in a suburban district but that was pretty much it." Casey, on the other hand, chose to complete all of her fieldwork in clinical, non-school settings: "I didn't have any experience at all in the schools before working at Cadillac Schools, I didn't know I was going to end up in the schools, I initially didn't plan on that." Casey articulated how difficult it was to complete her clinical fellowship (CF) with no experience at all in a school setting. On top of this, Casey's first exposure to the schools was in an urban intensive school, which presented her with significant challenges. Casey stated that, "It [Cadillac Schools] was very different than anything I was ever exposed to." Casey reflected on how "rough" that school year was and how many times she thought about leaving. To this end, Stacey stated, "Maybe if I had done an internship in a different location, I might have been more prepared. It's been challenging."

\section{Discussion}

Coursework. Ladson-Billings (2000) emphasized that faculty from programs that prepare individuals to work in schools ultimately have the responsibility to properly and effectively educate and prepare prospective professionals to work in urban schools regardless of the characteristics they may or may not possess. She believed this could be accomplished through academic experiences that explored the candidate's culture, other cultures, and the ways in which culture functions in education and society. However, for the participants in this study, culture seemed to be reduced to a single component. For example, Allison's foundational multicultural course focused solely on African American Vernacular English instead of exploring other cultures or culture in a more broad sense. Most general education teacher preparation programs utilized a foundational course approach for including multicultural content in the curriculum (Grant \& Secada, 1990; Ladson-Billings, 1995, McAllister \& Irvine, 2000; Zeichner, 1992) while speech-language pathology programs more often utilized the infusion approach (Stewart \& Gonzalez, 2002; Stockman, Boult, \& Robinson, 2004).

The participants in this study did not feel that they were given an adequate amount of multicultural coursework, whether it was via the foundational course or infusion approach. Approximately half of the SLPs experienced the foundational course approach to multicultural content while the other half experienced the infusion approach. The participants that experienced the foundational course approach distinctly remembered the course format and content associated with the class, whereas the participants who experienced the infusion approach recalled much less of how and what multicultural content was presented. For example, while Abby remembered that she had a professionalism course in conjunction with a clinical placement near the end of the program that addressed cultural competence in a superficial way, she commented that there was "really nothing of significance that I can recall." The participants felt that either approach implemented alone was problematic in that it did not adequately develop the cultural competence needed to work in urban schools.

Practicum. Professionals working in public schools have reported that no amount of coursework alone could have truly prepared them for teaching in the urban classroom (Ladson-Billings, 1994). Faculty in speech-language pathology preparation programs must be cognizant that while 
multicultural academic course work can be an important step toward cultural competence, true cultural competence amongst professionals does not merely come from academic knowledge of speech and language differences but also from experiences with people from diverse backgrounds (Laing \& Kamhi, 2003). The participants expressed this idea clearly throughout the interviews. To this end, Jenna made the analogy that "Just like learning a foreign language, being hands-on in a situation is going to be a better experience than learning from a book." One distinct and important way to gain these diverse experiences is through internships in urban schools. ASHA-accredited speech-language pathology programs were required to provide multicultural academic content in 1994, though it was not until 2005 that pre-service clinical experiences with diverse populations were mandated (Hammond, Mitchell, \& Johnson, 2009). Despite this mandate, many speech-language pathology program directors reported that providing students with clinical experiences with diverse populations was very challenging, especially in rural locations (Stewart \& Gonzalez, 2002). Quality internship placement has been found to be essential. Means (2009) found that more than $90 \%$ of surveyed programs' students completed an internship in a school setting. These student SLPs were highly influenced by their pre-service experiences. Casey represented the rare case of a person who did not complete an internship in the schools, as she did not anticipate working in an educational setting. All 10 of the other participants completed at least one internship in a school setting and explained how important and influential, for better or worse, their experiences were.

All of the participants spoke of very limited experiences with individuals from diverse backgrounds in their personal lives and education. This lack of diversity seemed to scare the participants away from work in urban schools, as none of the participants actively sought jobs in urban education. Rather, they came into work in urban schools due to not being able to find work in the medical setting, such as in Casey and Anna's case, mandatory placement from their contract company, like Rachel, Allison, and Abby faced, not being offered a job in a suburban school, which was Blair, Caroline, and Erin's situation, or demographic changes to the community where they have worked for an extended period of time, as Jennifer, Stacey, and Jenna experienced.

Students tend to enter academic programs viewing experiences from their own cultural perspective and have limited opportunities to engage in experiences with diverse cultural groups to build cultural competence (Hancock, 2011). Internship experiences in schools, particularly urban schools, can create the cognitive dissonance needed to progress toward cultural competence. Bucher (2004) theorized that cultural competence can be developed by pre-service clinicians through critically examining themselves and the world, increasing their knowledge of others experiences, becoming a witness to social injustices, and committing to action. By professionally interacting with individuals whose cultures differ from their own during preservice experiences, speech-language pathology students may experience challenges to their belief system and move beyond viewing experiences from their own cultural perspective, a necessary skill for working with CLD populations and progression toward cultural competence (Walters \& Geller, 2002). Furthermore, research has found that providing students the opportunity to serve in urban environments improved their levels of comfort and confidence in working with CLD students and increased their interest for employment in urban schools (Hampton, Peng, \& Ann, 2008; Koh, 2009; Schaffer, Gleich-Bope, \& Copich, 2014). Only three of the 11 participants in this study completed an internship in an urban school. Rachel, Jenna, 
and Abby all discussed the benefits of completing a pre-service experience in an urban school for their employment.

Beyond gaining rich pre-service experience in urban schools, successful education preparation programs have restructured field experiences to include immersion in urban communities (Coffey, 2010; Gallego, 2001; Ladson-Billings, 2000; Mahan, 1982). Urban community experiences have aided future educators in the ability to truly understand the realities of urban students, in context. Without the structure of the school, the potential urban employees are able to authentically witness the weaknesses, such as poor health care facilities, decreased and or delayed police and fire protection, and neglected play areas, and strengths, like the ways in which organizations such as churches support the community members, of the urban community (Ladson-Billings, 2000). Abby and Jenna were the only participants that spoke of experiences in the urban community outside of schools, although it should be noted these experiences were their choice and not a part of their SLP graduate school program. If SLP programs adopted the community immersion model of education programs, future SLP professionals would have a well-rounded experience, complete with diverse course and fieldwork.

While it is valid that the speech-language pathology preparation programs that the participants attended seemed to do little to prepare them for work in urban schools with CLD students, it could also be argued that placing the blame for this lack of preparedness solely on the programs was an act of defense. It is a more accepted vocabulary of motive (Mills, 1940) to claim that you are unprepared to work with students of color in urban schools because an academic program did not adequately address cultural competence than it is to admit that you have little to no experience interacting with individuals from diverse backgrounds. While the participants were eager to fault their graduate programs for not preparing them, they did not seem to believe their school districts or contract companies were responsible for ensuring that they received ongoing, proper training to be effective in the urban school environment.

\section{Implications}

Speech-language pathology preparation programs. While a multitude of research has been conducted on how to prepare teachers to work in the urban environment with students of color (Anderson \& Stillman, 2013; Darling-Hammond, 2006; Weiner, 2000), there are limited resources on how to do so for SLPs. While at times it is appropriate to examine research from related fields, it is imperative that the field of speech-language pathology produces its own research on how to best prepare SLPs to work with CLD students. The narratives from this study give valuable information for speech-language pathology preparation programs as to what may be missing from curriculum and internship experiences. While all participants were exposed to multicultural coursework in some way, none of them felt they had the opportunity to directly connect that information to the local, urban communities in which they could be employed. The speech-language pathology programs that the participants attended expected the students to independently apply general information about CLD groups to urban students once employed. While it may not be feasible to create a separate track for SLP students considering employment in urban schools, the present findings suggest that speech-language pathology programs would benefit from making urban education coursework readily available. 
Some programs have found creative ways to make this happen such as revamping courses to specifically address common challenges in local, urban schools, hiring professional consultants for faculty development, or collaborating with professionals across the campus who share an interest in urban education (Carter, Rudebusch, \& Lougeay, 2016; Roseberry-McKibbin, 2008; Walters \& Geller, 2002). In terms of internships, partnerships with local, urban school districts appeared to be the key to both provide experience for SLPs in an urban school setting where they can apply the information learned throughout coursework as well as to ease the burden of the urban SLP shortage (ASHA, 2010; Carter, Rudebusch, \& Lougeay, 2016; Walters \& Geller, 2002).

Cultural competence is defined as the awareness, understanding, appreciation, and sensitivity towards those individuals from diverse backgrounds (ASHA, n.d.-a). Instead of merely adding more multicultural courses to the curriculum, which label culturally and linguistically diverse (CLD) students as other, coursework should be reimagined to focus on the problematizing of the education system so that future professionals can critically question and explore the goals of education, curriculum, student-teacher relationship, and society (Zeichner, 1992). However, it has been reported that when some of the traditional students in higher education programs are presented with information about social inequities and anti-racist frameworks of teaching, they reject it (Grant, 1989; Haberman, 1991; King \& Ladson-Billings, 1990; Kohnert, 2013; Zeichner, 1992). Therefore, Ladson-Billings (2000) suggested a more systemic, comprehensive curriculum for preparation programs that includes autobiography studies, restructured field experiences, situated pedagogies, and expert urban teacher input and observations in order to increase the likelihood of cultural competency and effectively prepare professionals for work in urban schools with CLD students.

Coursework and clinical experiences about and with the urban community. Speechlanguage pathology programs need to provide students with more coursework and pre-service clinical experiences with diverse populations in urban settings. Several researchers have found that the combination of specific training and diverse cultural experiences appear to increase the confidence and competence of SLPs servicing individuals from CLD backgrounds (Caesar \& Kohler, 2007; Kritikos, 2003; Roseberry-McKibbin, Brice, \& O’Hanlon, 2005). However, it is essential that the coursework and experiences be directly tied to urban education in order to properly prepare future SLPs to work in urban schools. Core urban education concepts such as asset/deficit perspectives, connections with families, social justice, high learning expectations, and contextualized teaching and learning must be connected to the multicultural coursework and experiences (Rigoni, Pugach, Longwell-Grice, \& Ford, 2013). Sheepway, Lincoln, and McAllister (2014) found that clinical competency may not transfer across contexts. This means if we want to properly prepare students to work in urban settings, we must provide urban practicum experiences. Simply knowing about the speech and language features of a group does not translate into cultural competency.

It is not just that there needs to be more information on working with individuals from CLD backgrounds incorporated into preparation programs, greater care also needs to be taken with the content that is shared. While researchers such as Horton-Ikard, Munoz, Thomas-Tate, and Keller-Bell (2009) have outlined best practices for teaching a multicultural course in speechlanguage pathology, no one has identified content that is critical for preparing SLPs for working in urban schools. From the findings of this study it is clear that other models and theories besides 
the medical-model of disability need to be shared with the students, such as intersectionality (Crenshaw, 1991), the emic approach to evaluation (Berry, 1989; Hyter, Rivers, \& DeJarnette, 2015), cultural competency (Cross, Bazron, Dennis, \& Isaacs, 1989) or the International Classification of Functioning, Disability, and Health model (World Health Organization, 2007) in order to adequately prepare them for successful, effective careers in urban schools.

\section{Limitations}

This study is limited in that the data were from a small number of participants, all practicing in urban schools in the Midwest. In addition, only those SLPs who held a certificate of clinical competence were eligible for the study. While there are a large number of SLPs practicing in urban schools in their clinical fellowship year, the rationale for this choice was that clinical fellows are still practicing their clinical skills and a deeper understanding of urban special education processes and procedures was desired. A larger participant pool from various geographic locations would be needed in order to provide a more nuanced perspective about the preparation of SLPs working in urban schools. It should also be noted that despite all preparation practices in speech-language pathology programs, implicit personal bias and beliefs might impact professional practice with individuals from CLD backgrounds.

\section{Conclusion}

The results of this study provide evidence to support the idea that coursework and practicum experiences combined are essential to adequately preparing SLPs to work in urban schools with culturally and linguistically diverse students. The results suggest that by implementing changes to coursework and practicum in higher education, not only will SLPs feel more culturally competent and better prepared to work in urban schools, but it could also significantly impact the shortage of urban, school-based SLPs. The findings present the thought that preparation to work with individuals from CLD backgrounds and preparation to work in urban schools with CLD students are really two different ideas and thus should be addressed as such throughout higher education coursework and practicum experiences. If SLPs had coursework and practicum experiences that connected multicultural and urban information, interest in working for urban schools could be stimulated. In this way, beginning SLPs could stop seeing urban schools as a place to get experience before leaving for a suburban district and start seeing urban education as a legitimate, long-term career setting. 


\section{References}

American Speech-Language-Hearing Association (ASHA). (n.d.-a). Cultural competence. Rockville, MD: Author. Retrieved from http://www.asha.org/PracticePortal/Professional-Issues/Cultural-Competence/

American Speech-Language-Hearing Association (ASHA). (n.d.-b). Multicultural/Multilingual issues in CSD curricula: Resources for infusion. Rockville, MD: Author. Retrieved from http://www.asha.org/practice/multicultural/faculty/mmi/

American Speech-Language-Hearing Association (ASHA). (2010). How does one urban program manage clinical education? Rockville, MD: Author. Retrieved from http://www.asha.org/Academic/questions/urban-program-clinical-education/

American Speech-Language-Hearing Association (ASHA). (2016). 2016 Schools survey. Survey summary report: Number and type of responses, SLPs. Rockville, MD: Author. Retrieved from http://www.asha.org/uploadedFiles/2016-Schools-Summary-Report.pdf

American Speech-Language-Hearing Association (ASHA). (2017). Highlights and trends: Member and affiliate counts, year-end 2016. Rockville, MD: Author. Retrieved http://www.asha.org/uploadedFiles/2016-Member-Counts.pdf

American Physical Therapy Association (2014). Blue print for teaching cultural competence in physical therapy education. Alexandria, VA: Author. Retrieved from https://www.apta.org/Educators/Curriculum/APTA/CulturalCompetence/

Anderson, L. M., \& Stillman, J. A. (2013). Student teaching's contribution to preservice teacher development: A review of research focused on the preparation of teachers for urban and high-needs contexts. Review of Educational Research, 83(1), 3.

Bales, B. L., \& Saffold, F. (2011). A new era in the preparation of teachers for urban schools: Linking multiculturalism, disciplinary-based content, and pedagogy. Urban Education, 46(5), 953-974. doi:10.1177/0042085911400320

Berry, J.W. (1989). Imposed etics, emics, derived etics. International Journal of Psychology, $24,721-735$.

Brantlinger, E., Jimenez, R., Klingner, J., Pugach, M., \& Richardson, V. (2005). Qualitative studies in special education. Exceptional Children, 71(2), 195-207.

Bucher, R. D. (2004). Diversity consciousness: Opening our minds to people, cultures, and opportunities. Upper Saddle River, NJ: Pearson/Prentice Hall.

Caesar, L. G., \& Kohler, P. D. (2007). The state of school-based bilingual assessment: Actual practice versus recommended guidelines. Language, Speech, and Hearing Services in Schools, 38, 190-200.

Carter, J., Rudebusch, J., \& Lougeay, J. (2016). UT Dallas partnership tackles SLP shortage in urban areas. ASHA Leader, 21(7), 34. doi:10.1044/leader.AE.21072016.34

Coffey, H. (2010). "They taught me": The benefits of early community-based field experiences in teacher education. Teaching and Teacher Education, 26(2), 335-342. doi:10.1016/j.tate.2009.09.014

Council for Clinical Certification in Audiology and Speech-Language Pathology of the American Speech-Language-Hearing Association. (2013). 2014 standards for the certificate of clinical competence in speech-language pathology. Rockville, MD: Author. Retrieved from http://www.asha.org/Certification/2014-Speech-Language-PathologyCertification-Standards/.

Crenshaw, K. (1991). Mapping the margins: Intersectionality, identity politics, and violence against women of color. Stanford Law Review 43(6): 1241-1299. 
Creswell, J. W. (2013). Qualitative inquiry and research design: Choosing among five traditions. Thousand Oaks, CA: Sage Publications.

Cross, T., Bazron, B., Dennis, K., \& Isaacs, M. (1989). Towards a culturally competent system of care, Volume I. Washington, DC: CAASP Technical Assistance Center, Georgetown University Child Development Center.

Darling-Hammond, L. (2006). Powerful teacher education: Lessons from exemplary programs. San Francisco, CA: Jossey-Bass.

Gallego, M. A. (2001). Is experience the best teacher?: The potential of coupling classroom and community-based field experiences. Journal of Teacher Education, 52(4), 312-325. doi:10.1177/0022487101052004005

Geertz, C. (1973). The interpretation of cultures. New York, NY: Basic Books.

Glesne, C. (2006). Becoming qualitative researchers: An introduction. Boston, MA: Pearson.

Gonzalez, R. J., Pagan, M., Wendell, L., \& Love, C. (2011). Supporting ELL/culturally and linguistically diverse students for academic achievement. Retrieved from http://www.brown.edu/academics/education-alliance/teaching-diverselearners/sites/brown.edu.academics.education-alliance.teaching-diverselearners/files/uploads/

Grant, C. A. (1989). Urban teachers: Their new colleagues and curriculum. Phi Delta Kappan, 70, 764-770.

Grant, C. A., \& Secada, W. (1990). Preparing teachers for diversity. In W. R. Houston, M. Haberman, \& J. Sikula (Eds.), Handbook of research on teacher education (pp. 403-422). New York, NY: Macmillan.

Haberman, M. (1991). Can cultural awareness be taught in teacher education programs? Teaching Education, 4, 25-32.

Hammond, C., Mitchell, P., \& Johnson, M. (2009). Academic and clinical preparation for cultural and linguistic diversity in speech-language pathology: Program director perspectives. Contemporary Issues in Communication Science and Disorders, 36, 63.

Hampton, B., Peng, L., \& Ann, J. (2008). Pre-service teachers' perceptions of urban schools. The Urban Review, 40(3), 268-295. doi:10.1007/s11256-008-0081-2

Hancock, S. (2011). White women's work: On the front lines in urban education. In J. G. Landsman \& C. W. Lewis, (Eds.), White teachers/diverse classrooms: Creating inclusive schools, building on students' diversity, and providing true educational equity (pp. 91-109). Sterling, VA: Stylus Publishing.

Horton-Ikard, R., Munoz, M. L., Thomas-Tate, S., \& Keller-Bell, Y. (2009). Establishing a pedagogical framework for the multicultural course in communication sciences and disorders. American Journal of Speech-Language Pathology, 18(2), 192-206. doi:10.1044/1058-0360(2008/07-0086)

Hycner, R. H. (1985). Some guidelines for the phenomenology analysis of interview data. Human Studies, 8(2), 279-303.

Hyter, Y.D., Rivers, K.O., \& DeJarnette, G. (2015). Pragmatic language of African American children and adolescents: A systematic synthesis of the literature. Topics in Language Disorders, 35(1), 8-45.

Kincheloe, J. (2007). Why a book on urban education? In S. Steinberg \& J. Kincheloe (Eds.), 19 urban questions: Teaching in the city (pp.1-27). New York, NY: Peter Lang. 
King, J., \& Ladson-Billings, G. (1990). The teacher education challenge in elite university settings: Developing critical perspectives for teaching in a democratic and multicultural society. European Journal of Intercultural Studies, 1, 15-30.

Koh, M. (2009). Practice teaching in urban schools: The effectiveness of special education preclinical experience in urban school settings. The Scholarship of Teaching and Learning at EMU, 1(6).

Kohnert, K. (2013). One insider's reflections on white privilege, race and their professional relevance. Perspectives on Communication Disorders and Sciences in Culturally and Linguistically Diverse Populations, 20(2), 41-48. doi:10.1044/cds20.2.41

Kritikos, E. P. (2003). Speech-language pathologists' beliefs about language assessment of bilingual/bicultural individuals. American Journal of Speech-Language Pathology, 12, 73-91.

Ladson-Billings, G. (1994). Who will teach our children? Preparing teachers to teach African American learners. In E. Hollins, J. King, \& W. Hayman (Eds.), Teaching diverse learners: Formulating a knowledge base for teaching diverse populations (pp. 129-158). Albany, NY: State University of New York Press.

Ladson-Billings, G. (1995). Toward a theory of culturally relevant pedagogy. American Educational Research Journal, 32(3), 465-491. doi:10.2307/1163320

Ladson-Billings, G. (1999). Preparing teachers for diversity: Historical perspectives, current trends, and future directions. In L. Darling-Hammond \& G. Sykes (Eds.), Teaching as the learning profession: Handbook of policy and practice (pp. 86-123). San Francisco, CA: Jossey-Bass.

Ladson-Billings, G. (2000). Fighting for our lives: Preparing teachers to teach African American students. Journal of Teacher Education, 51(3), 206-214. doi:10.1177/0022487100051003008

Laing, S., \& Kamhi, A. (2003). Alternative assessment of language and literacy in culturally and linguistically diverse populations. Language, Speech, and Hearing Services in Schools, 34, 44-55.

Mahan, J. (1982). Native Americans as teacher trainers: Anatomy and outcomes of a cultural immersion project. Journal of Educational Equity and Leadership, 2, 100-110.

McAllister, G., \& Irvine, J. J. (2000). Cross cultural competency and multicultural teacher education. Review of Educational Research, 70(1), 3-24. doi:10.2307/1170592

Means, J. (2009). Academic preparation for the school-based SLP: A national survey. SIG 16, Perspectives on School-Based Issues, 10, 96-100.

Mills, C. W. (1940). Situated actions and vocabularies of motive. American Sociological Review, 5(6), 904-913.

Milner, H. R. (2006). Preservice teachers' learning about cultural and racial diversity: Implications for urban education. Urban Education, 41, 343-375.

Milner, H. R. (2012). But what is urban education? Urban Education, 47(3), 556-561.

Mustian, A. L., Lee, R. E., Nelson, C., Gamboa-Turner, V., \& Roule, L. (2017). Jumping into the deep end: Developing culturally responsive urban teachers through communityimmersive partnerships. The Educational Forum, 81(4), 467. doi:10.1080/ 00131725.2017.1350239

National Center for Education Statistics. (2017). The condition of education: Racial/Ethnic enrollment in public schools. Washington D.C.: Author. Retrieved from https://nces.ed.gov/programs/coe/indicator_cge.asp 
Rigoni, K. K., Pugach, M. C., Longwell-Grice, H., \& Ford, A. (2013). A programmatic view of portfolios for urban teacher preparation: A second look. Education and Urban Society, 45(1), 88-119. doi:10.1177/0013124511408598

Robertson, P. M., García, S. B., McFarland, L. A., \& Rieth, H. J. ( 2012 ). Preparing culturally and linguistically responsive special educators: It "does" take a village. Interdisciplinary Journal of Teaching and Learning, 2(3), 115 - 130.

Ronfeldt, M. (2012). Where should student teachers learn to teach? Effects of field placement school characteristics on teacher retention and effectiveness. Educational Evaluation and Policy Analysis, 34(1), 3-26. doi:10.3102/0162373711420865

Roseberry-McKibbin, C. (2008). Multicultural students with special language needs: Practical strategies for assessment and intervention (3rd ed.). Oceanside, CA: Academic Communication Associates.

Roseberry-McKibbin, C., Brice, A., \& O’Hanlon, L. (2005). Serving English language learners in public school settings: A national survey. Language, Speech, and Hearing Services in Schools, 36, 48-61.

Schaffer, C., Gleich-Bope, D., \& Copich, C. (2014). Urban immersion: Changing pre-service teachers' perceptions of urban schools. The Nebraska Educator: A Student-Led Journal. Paper 19.

Schram, T. H. (2006). Conceptualizing and proposing qualitative research. Upper Saddle River, NJ: Pearson Merrill Prentice Hall.

Seidman, I. (2006). Interviewing as qualitative research: A guide for researchers in education and the social sciences. New York, NY: Teachers College Press.

Sheepway, L., Lincoln, M., \& McAllister, S. (2014). Impact of placement type on the development of clinical competency in speech-language pathology students: Competency development in speech-language pathology students. International Journal of Language \& Communication Disorders, 49(2), 189-203. 10.1111/1460-6984.12059

Sheepway, L., Lincoln, M., \& Togher, L. (2011) An international study of clinical education practices in speech-language pathology. International Journal of Speech-Language Pathology, 13, 174-185.

Stewart, S. R., \& Gonzalez, L. S. (2002). Serving a diverse population: The role of speech language pathology professional preparation programs. Journal of Allied Health, 31(4), 204-216.

Stockman, I. J., Boult, J., \& Robinson, G. (2004). Multicultural issues in academic and clinical education: A cultural mosaic. ASHA Leader, 9(13), 6.

Villegas, A. M., \& Irvine, J. J. (2010). Diversifying the teaching force: An examination of major arguments. The Urban Review, 42(3), 175-192. doi:10.1007/s11256-010-01501

Walters, S., \& Geller, E. (2002). The evolution of an urban bilingual/ multicultural graduate program in speech-language pathology. Contemporary Issues in Communication Science and Disorders, 29, 185-193.

Weiner, L. (2000). Research in the 90s: Implications for urban teacher preparation. Review of Educational Research, 70(3), 369-406. doi:10.2307/1170787

Wilson, S. M., Floden, R. E., \& J. Ferrini-Mundy (2001). Teacher preparation research: Current knowledge, gaps, and recommendations. Retrieved from https://www.education.uw.edu/ctp/sites/default/files/ctpmail/PDFs/TeacherPrep-WFFM02-2001.pdf 
World Health Organization (2007). International classification of functioning, disability and health: Children \& youth version: ICF-CY. Geneva, Switzerland: Author.

Zeichner, K. (1992). Educating teachers for cultural diversity (Special Report). East Lansing, MI: National Center for Research on Teacher Learning. Retrieved from https://education.msu.edu/NCRTL/PDFs/NCRTL/SpecialReports/sr293.pdf

Zeichner, K. (2003). The adequacies and inadequacies of three current strategies to recruit, prepare and retain the best teachers for all students. Teachers College Record, 105, 490519.

Zeichner, K. (2010). Rethinking the connections between campus courses and field experiences in college and university-based teacher education. Journal of Teacher Education, 61(12), 89-99. 